\title{
Assessment of the suitability of dry yeast for the production of wines and wine beverages from sea buckthorn
}

\author{
Evgeny Rozhnov ${ }^{1,2}$, Marina Scholnikova ${ }^{1}$, and Olga Chugunova ${ }^{1, *}$ \\ ${ }^{1}$ Ural State Economic University, 8 Marta, 62, 620144 Yekaterinburg, Russia \\ ${ }^{2}$ Biysk Technological Institute (branch) Altai State Technical University named after I.I. Polzunov, \\ Geroya Sovetskogo Soyuza Trofimova Str., 27, 659305 Biysk, Russia
}

\begin{abstract}
Biochemical transformations under the action of the yeast enzyme complex affect not only the utilization of sugar to the final product - ethyl alcohol, but also secondary processes accompanied by the synthesis of minor side components that have a significant impact on the bouquet and taste of finished drinks. Modern dry yeast for winemaking produced industrially is characterized by significant variability in characteristics, which requires testing of their use on various types of raw materials. In the experiment, data were obtained on the use of dry yeast produced by LALLEMAND Inc. company (Canada) for the production of sea buckthorn wines and wine beverages. It is established that the studied yeast samples allow to obtain a finished product with different characteristics, which makes it possible to differentially approach the industrial implementation of the technology of wines and wine drinks from sea buckthorn by varying the yeast strains.
\end{abstract}

\section{Introduction}

The conditions and stability of fruit wines depend on both the technological solutions used and the yeast used [1-3]. As biochemical transformations under the action of the enzyme complex affect not only the utilization of sugar to the final product - ethyl alcohol, but also secondary processes accompanied by the synthesis of minor side components that have a significant impact on the bouquet and taste of finished drinks [4-8].

Currently, wine scientists are searching for new yeast strains that have unique properties, such as those capable of supersynthesis of compound ethers that give wines fruit and floral tones, or terpene compounds that give wines light citrus notes [9-14].

In addition, with the development of concepts on yeast cells metabolism, so-called killer yeast has been obtained, which can suppress the development of foreign microflora in fermenting wort by releasing toxins that are harmful to the cells of foreign microorganisms [15-18].

Of practical interest is the study of new commercial strains of dry yeast, the properties of which are insufficiently studied in the production of fruit wines.

\footnotetext{
${ }^{*}$ Corresponding author: chugunova@usue.ru
} 
The objective of this research was to study and compare commercial preparations of active dry yeast Saccharomyces cerevisiae and interspecific hybrid Saccharomyces cerevisiae var. bayanus when used in the technology of fruit wines and wine drinks from sea buckthorn fruits.

Of practical interest is the study of new commercial strains of dry yeast, the properties of which are insufficiently studied in the production of fruit wines.

\section{Objects and methods of research}

During the experiments, the following dry yeast preparations were used as research objects:

LALVIN QA23 ${ }^{\mathrm{TM}}$ (LALLEMAND Inc., Canada) - wine yeast of the Saccharomyces cerevisiae var. bayanus species, which has a killer factor in relation to foreign microorganisms of the wort and improves the varietal character of the wine. They provide fast fermentation of wort with a high level of glycerol reduction and a slight accumulation of acetaldehyde. The optimal temperature of use is $14-28{ }^{\circ} \mathrm{C}$, the need for nitrogen is low, and up to $16 \%$ alcohol is kept in the medium;

LALVIN 71B ${ }^{\mathrm{TM}}$ (LALLEMAND Inc., Canada) - wine yeast of the Saccharomyces cerevisiae species that has a high ether-forming ability. It provides a moderate rate of fermentation of the wort with a short duration of the lag phase. It is characterized by a high ability to accumulate glycerol in the wort and extremely low formation of acetaldehyde. Undemanding to nitrogen nutrition. The optimal temperature of use is $15-30{ }^{\circ} \mathrm{C}$, it can withstand up to $14 \%$ alcohol in the medium;

LALVIN EC1118 ${ }^{\mathrm{TM}}$ (LALLEMAND Inc., Canada) - wine yeast of the Saccharomyces cerevisiae var. bayanus species, which has a killer factor in relation to foreign microorganisms of the wort. It does not affect the varietal aroma of wine. It is characterized by a high rate of wort fermentation with a short lag phase. It accumulates a high amount of glycerol in the fermenting wort. The optimal temperature of use is $10-30{ }^{\circ} \mathrm{C}$, it can withstand up to $16 \%$ alcohol in the medium; It has a low need for nitrogen nutrition.

LALVIN ICV D47TM (LALLEMAND Inc., Canada) is a wine yeast of the Saccharomyces cerevisiae var. cerevisiae species, characterized by a moderate fermentation rate of the wort with a very short lag phase. Undemanding to nitrogen nutrition. The optimal temperature of use is $15-30{ }^{\circ} \mathrm{C}$, it can withstand up to $14 \%$ alcohol in the medium;

LALVIN ICV OPALETM (LALLEMAND Inc., Canada) - wine yeast of the Saccharomyces cerevisiae var. cerevisiae species, that can improve the varietal aroma of wine and its organoleptic perception. It is characterized by a moderate fermentation rate of the wort with a very short lag phase. It provides moderate accumulation of glycerol, with a high level of reduction of acetaldehyde. Undemanding to nitrogen nutrition. The optimal temperature of use is $15-30{ }^{\circ} \mathrm{C}$, it can withstand up to $16 \%$ alcohol in the medium;

As a control, dry wine yeast of industrial application LEVURE IOC 11-1002 (Institut Oenologique de Champagne, France), belonging to the Saccharomyces cerevisiae species, withstanding up to $15 \%$ alcohol in the medium and providing a uniform and complete fermentation process without giving specific tones to the finished wine, was used.

Fermentation was performed using a composition-adjusted sea buckthorn wort obtained from sea buckthorn juice of direct extraction with a titratable acidity of $11.3 \pm 0.3 \mathrm{~g} / \mathrm{dm}^{3}$ and a sugar content of $83.2 \pm 3.5 \mathrm{~g} / \mathrm{dm}^{3}$. The wort was adjusted using the classic method for fruit winemaking using a method of dilution with water to a titratable acidity of $7.0 \mathrm{~g} / \mathrm{dm}^{3}$ and adding granulated sugar to a sugar concentration of $200 \mathrm{~g} / \mathrm{dm}^{3}$. Fermentation of the control and experimental wort was carried out under the same conditions at a temperature of 22-24 ${ }^{\circ} \mathrm{C}$.

The values of the main physical and chemical parameters were determined using standard methods and methods generally accepted in the industry [19]. The composition of volatile 
components of sea buckthorn wine samples was determined by gas chromatography (Chromos GH-1000.1, Russia) using a capillary column of the HP-FFAP type with dimensions of $50 \mathrm{~m} \times 0.25 \mathrm{~mm}$. Sample input - dosing of the equilibrium vapor phase with an equilibrium vapor dispenser. The initial temperature of the column is $75^{\circ} \mathrm{C}$ with an exposure of 5 minutes, then the column temperature rises to $140{ }^{\circ} \mathrm{C}$ at a speed of $3{ }^{\circ} \mathrm{C} / \mathrm{min}$, exposure for 10 minutes, then the column temperature rises to $220{ }^{\circ} \mathrm{C}$ at a speed of $5{ }^{\circ} \mathrm{C} / \mathrm{min}$ and exposure at this temperature for 10 minutes. The total analysis time is 60 minutes. The composition of organic acids of wine was determined by capillary electrophoresis (Kapel 105M, Russia)

\section{Research results and their discussion}

When determining organic acids, it was found (table 1) that the yeast LALVIN EC1118 and LALVIN QA23 have the ability to reduce the concentration of hydroxy-succinic acid, which allows to conclude about the distinctive features of the metabolism of these yeast races, apparently associated with the presence in their cells of more active enzyme systems responsible for regulating the Krebs cycle.

Table 1. Dynamics of organic acids in experimental samples.

\begin{tabular}{|l|c|c|c|c|c|c|}
\hline \multirow{2}{*}{$\begin{array}{c}\text { Mass acid } \\
\begin{array}{c}\text { concentration } \\
\mathrm{g} / \mathrm{dm}^{3}\end{array}\end{array}$} & $\begin{array}{c}\text { LALVIN } \\
\text { QA23 }\end{array}$ & $\begin{array}{c}\text { LALVIN } \\
71 \mathrm{~B}\end{array}$ & $\begin{array}{c}\text { LALVIN } \\
\text { EC1118 }\end{array}$ & $\begin{array}{c}\text { LALVIN } \\
\text { ICV D47 }\end{array}$ & $\begin{array}{c}\text { LALVIN } \\
\text { ICV } \\
\text { OPALE }\end{array}$ & $\begin{array}{c}\text { LEVURE } \\
\text { IOC 11- } \\
1002\end{array}$ \\
\hline wine & $0.22 \pm 0.01$ & $0.26 \pm 0.01$ & $0.24 \pm 0.02$ & $0.23 \pm 0.01$ & $0.23 \pm 0.02$ & $0.24 \pm 0.02$ \\
\hline $\begin{array}{l}\text { hydroxy-succinic } \\
\text { apple) }\end{array}$ & $4.83 \pm 0.03$ & $5.02 \pm 0.02$ & $4.91 \pm 0.02$ & $5.08 \pm 0.03$ & $5.04 \pm 0.02$ & $5.08 \pm 0.03$ \\
\hline succinate (amber) & $0.44 \pm 0.02$ & $0.38 \pm 0.02$ & $0.42 \pm 0.01$ & $0.71 \pm 0.02$ & $0.64 \pm 0.01$ & $0.58 \pm 0.02$ \\
\hline citric & $0.89 \pm 0.01$ & $0.83 \pm 0.02$ & $0.86 \pm 0.02$ & $0.88 \pm 0.04$ & $0.83 \pm 0.01$ & $0.87 \pm 0.02$ \\
\hline acetic & $0.29 \pm 0.01$ & $0.31 \pm 0.02$ & $0.42 \pm 0.03$ & $0.34 \pm 0.02$ & $0.37 \pm 0.01$ & $0.30 \pm 0.01$ \\
\hline lactic & no & $0.34 \pm 0.03$ & $0.31 \pm 0.02$ & no & $0.27 \pm 0.03$ & $0.32 \pm 0.02$ \\
\hline
\end{tabular}

At the same time, the yeast LALVIN ICV D47 and LALVIN ICV OPALE can be considered as amberogenic, since they provide an accumulation of succinate acid above the control level. The possibility of super-synthesis of succinate acid by yeast in the production of wine products should be considered as a positive moment, since the synergistic effect between succinate acid, polyphenols and other substances that provide antioxidant activity, causes an increase in the physiological value of wines and wine drinks.

The mass concentration of volatile organic acids for all samples of sea buckthorn wines obtained using the studied yeast had similar values and ranged from $0.45 \mathrm{~g} / \mathrm{dm}^{3}$ (for LALVIN QA23) to $0.58 \mathrm{~g} / \mathrm{dm}^{3}$ (for LALVIN EC1118).

Figure 1 shows the results of determining the accumulation of glycerol in sea buckthorn wine samples. It can be seen that the lowest amount of glycerol is characteristic of the yeast LALVIN ICV OPALE, which is noted by the manufacturer in the specification. The remaining yeast, including the control, accumulates an average of 35-45\% more glycerol compared to the LALVIN ICV OPALE yeast. 


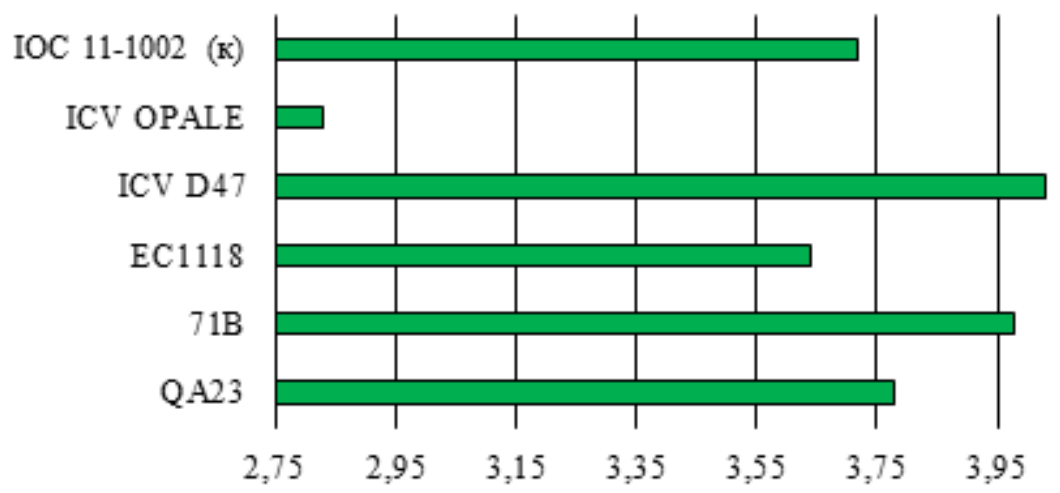

Glycerol mass concentration, $\mathrm{g} / \mathrm{dm}^{3}$

Fig. 1. The content of glycerol in the test samples.

Thus, low concentrations of volatile organic acids, with a sufficiently high level of glycerol accumulation, may indicate an intensive glyceropyruvic fermentation, which is a side effect and, according to Neiberg's work, occurs in parallel with alcohol one [20]. Depending on the activity of the enzyme systems responsible for the implementation of this metabolic pathway, the yeast cell can consume up to $10 \%$ of all wort sugars for its implementation. The implementation of glyceropyruvic fermentation leads to the accumulation of glycerol in the wine [21, 22], which gives the finished product a soft and velvety taste, as well as pyruvic acid, which is an intermediate for the subsequent biosynthesis of acetaldehyde, some organic acids (including succinate acid) and a number of other compounds that affect the taste and bouquet of wine. At the same time, it is known that during glyceropyruvic fermentation, some volatile organic acids enter into further reactions, and the amount of acetoin and vicinal diketones formed, which have a low sensitivity threshold, becomes extremely small.

It is a well-known fact that some polyphenolic substances with a negative total charge are sorbed on the surface of yeast cells. As a result of research, it was found that when using the yeast LALVIN ICV OPALE and LALVIN EC1118 in fermented wine materials, the concentration of phenolic substances was at a higher level than in other yeast samples (Fig. 2).

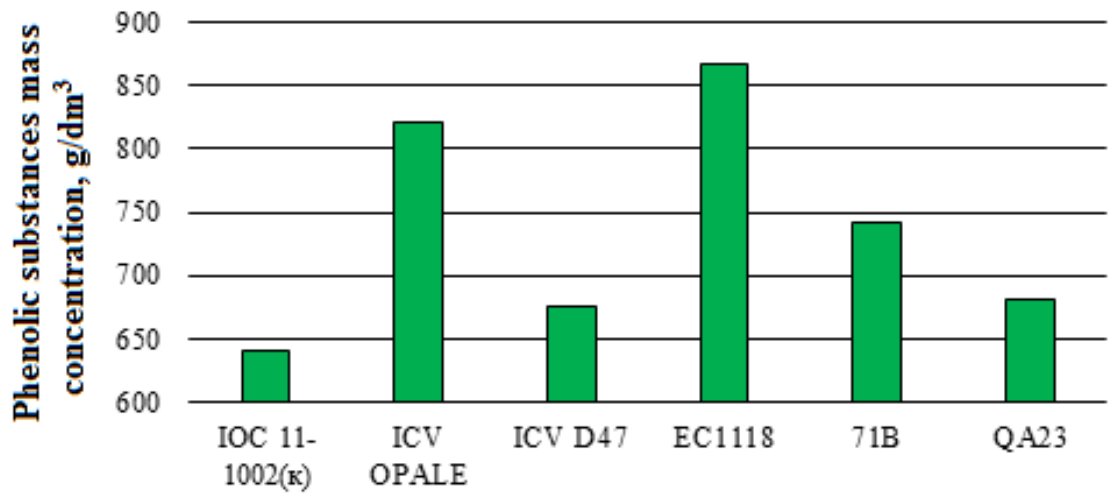

Fig. 2. Content of phenolic substances in experimental samples. 
On the one hand, this can be explained by the low ability of the yeast cells surface to bind phenolic substances, and on the other - by the peculiarities of the metabolism of yeast cells, which exclude or have little effect on the oxidation of polyphenols during fermentation.

In the obtained samples of sea buckthorn wines, the composition of fermentation products was determined. Eypical chromatogram is shown in figure 3. The results of determination of biosynthesis products are summarized in table 2 .

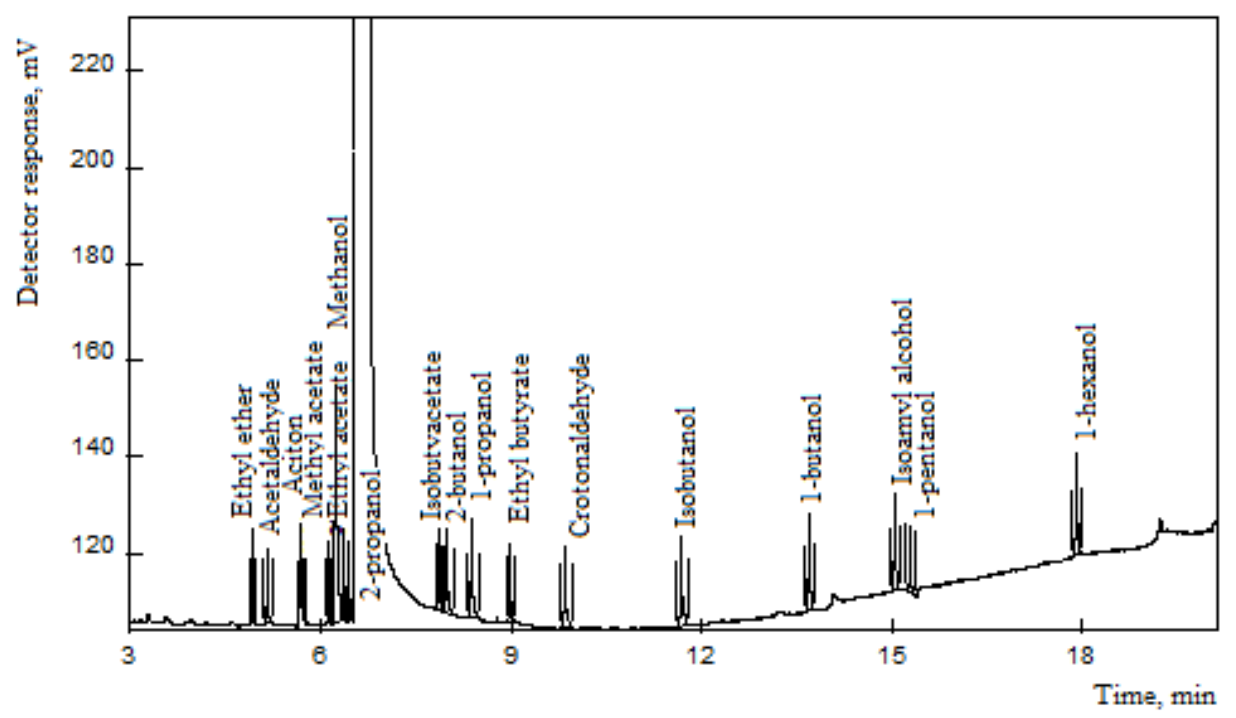

Fig. 3. Chromatogram of sea buckthorn wine fermentation by-products.

It can be seen that the yeast LALVIN QA23, LALVIN EC1118, LALVIN ICV OPALE have a reduction level of fermentation by-products higher than in the control sample. LALVIN 71B yeast is characterized by a low level of formation of fermentation by-products, which makes it possible to obtain wines and wine drinks with a varietal bouquet due to the aromatic substances of the raw material.

Table 2. The content of some products of yeast biosynthesis in sea buckthorn wines.

\begin{tabular}{|l|c|c|c|c|c|c|}
\hline \multirow{2}{*}{ Component name } & \multicolumn{6}{|c|}{ Wine material and active dry yeast preparation } \\
\cline { 2 - 7 } & $\begin{array}{c}\text { IOC 11- } \\
1002(\mathrm{\kappa})\end{array}$ & $\begin{array}{c}\text { ICV } \\
\text { OPALE }\end{array}$ & ICV D47 & EC1118 & $71 \mathrm{~B}$ & QA23 \\
\hline Higher alcohols: & 402.29 & 420.45 & 461.32 & 413.39 & 442.13 & 423.88 \\
\hline propanol-1 & 5.87 & 6.34 & 9.27 & 5.68 & 10.37 & 6.02 \\
\hline butanol-1 & 0.58 & 0.39 & 1.83 & 0.49 & 2.04 & 0.63 \\
\hline butanol-2 & - & 0.05 & 0.18 & - & 0.11 & - \\
\hline isobutanol & 186.39 & 198.57 & 237.62 & 187.31 & 224.65 & 191.64 \\
\hline pentanol-1 & 0.16 & 0.24 & 0.67 & 0.23 & 0.51 & 0.11 \\
\hline isoamylol & 207.62 & 213.54 & 208.64 & 218.49 & 201.67 & 223.84 \\
\hline hexanol-1 & 1.67 & 1.32 & 3.11 & 1.19 & 2.78 & 1.64 \\
\hline Aromatic alcohols: & 54.44 & 48.89 & 30.71 & 51.47 & 26.15 & 54.72 \\
\hline benzyl & 1.02 & 1.24 & 1.36 & 1.11 & 1.48 & 1.08 \\
\hline 2-phenylethanol & 53.42 & 47.65 & 29.35 & 50.36 & 24.67 & 53.64 \\
\hline Aldehydes: & 19.49 & 16.6 & 6.52 & 18.85 & 8.13 & 20.04 \\
\hline benzaldehyde & 0.78 & 0.36 & - & 0.47 & - & 0.29 \\
\hline
\end{tabular}




\begin{tabular}{|c|c|c|c|c|c|c|}
\hline acetaldehyde & 18.71 & 16.24 & 6.52 & 18.38 & 8.13 & 19.75 \\
\hline Ethers: & 54.23 & 48.77 & 18.27 & 51.75 & 21.66 & 48.91 \\
\hline ethylacetate & 54.23 & 48.77 & 18.27 & 51.75 & 21.66 & 48.91 \\
\hline $\begin{array}{c}\text { Eotal amount of } \\
\text { biosynthesis } \\
\text { products }\end{array}$ & 530.45 & 534.71 & 516.82 & 535.46 & 498.07 & 547.55 \\
\hline
\end{tabular}

\section{Conclusions}

As a result of the research, it was found that each yeast test sample can be used depending on the technological goals pursued:

1) yeast LALVIN EC1118 and LALVIN QA23 have the ability to reduce the concentration of hydroxy-succinic acid. At the same time, the yeast LALVIN ICV D47 and LALVIN ICV OPALE provide an accumulation of succinate acid above the control level;

2) amount of synthesized glycerol for LALVIN ICV OPALE yeast is 35-40\% less compared to all other yeast samples studied;

3) when using the yeast LALVIN ICV OPALE and LALVIN EC1118 in fermented wine materials, the concentration of phenolic substances was 15-35\% higher compared to other yeast samples.

4) yeast LALVIN QA23, LALVIN EC1118, LALVIN ICV OPALE can accumulate a large number of fermentation by-products in wines, which has a positive effect on the organoleptic characteristics of wines and wine drinks from sea buckthorn.

Thus, all the studied yeast samples can be recommended for use in the production of wines and wine drinks from sea buckthorn fruit.

Conflict of interest. The authors declare that there is no conflict of interest.

Compliance with ethical standards. This article does not contain researches involving animals or humans performed by any of the authors.

\section{References}

1. J.C. Zhu, Y.W. Niu, T. Feng, S.J. Liu, H.X. Cheng, N. Xu, H.Y. Yu, Z.B. Xiao, Natural Product Research, 28:21 (2014)

2. P. Mena, A. Gironés-Vilaplana, N. Martí, C. García-Viguera, C., Food Chemistry, 133(1) (2012)

3. G.H. Fleet, Current Opinion in Biotechnology, 18(2) (2007)

4. A. Teixeira, N. Baenas, R. Dominguez-Perles, A. Barros, E. Rosa, D. Moreno, C. Garcia-Viguera, International Journal of Molecular Sciences, 15(9) (2014)

5. V. Verardo, A. M. Gómez-Caravaca, G. Tabanelli, Foods, 9(2) (2020)

6. L. Marchante, L. Loarce, P. M. Izquierdo-Cañas, M. E. Alañón, E. García-Romero, M. S. Pérez-Coello, M. C. Díaz-Maroto, Food Research International, 108594 (2019)

7. T. Román Villegas, L. Tonidandel, B. Fedrizzi, R. Larcher, G. Nicolini, Food Chemistry, 207 (2016)

8. E. Bardi, A. A. Koutinas, C. Psarianos, M. Kanellaki, Process Biochemistry, 32(7) (1997)

9. S.M.G. Saerens, F.R. Delvaux, K.J. Verstrepen, J.M. Thevelein, Microbial Biotechnology, 3(2) (2010)

10. S. Rollero, J.-R. Mouret, I. Sanchez, C. Camarasa, A. Ortiz-Julien, J.-M. Sablayrolles, S. Dequin, Microbial Cell Factories, 15(1) (2016) 
11. S. Rollero, A. Bloem, C. Camarasa, I. Sanchez, A. Ortiz-Julien, J.-M. Sablayrolles, Applied Microbiology and Biotechnology, 99(5) (2014)

12. K. Hu, G.-J. Jin, W.-C. Mei, T. Li, Y.-S. Tao, Food Chemistry, 239 (2018)

13. K. Šklje, G. Antalick, A. Buica, Z.A. Coetzee, J. Brand, L.M. Schmidtke, M.A. Vivier, Food Chemistry, 197 (2016)

14. F. Casu, F. R. Pinu, B. Fedrizzi, D. R. Greenwood, S. G. Villas-Boas, FEMS Yeast Research, 16(5) (2016)

15. M. Ciani, F. Comitini, Current Opinion in Food Science, 1 (2015)

16. Z. Liu, S. Du, Y. Ren, Y. Liu, Journal of Basic Microbiology, 58(1) (2017)

17. R. Velázquez, E. Zamora, M. Álvarez, M. L. Álvarez, M. Ramírez, Food Microbiology, 59 (2016)

18. M. Ciani, A. Capece, F. Comitini, L. Canonico, G. Siesto, P. Romano, Frontiers in Microbiology, 7 (2016)

19. V.G. Gerzhikova, Methods technochemical control in the wine industry (2009)

20. C. Neuberg, M. Kobel, Journal of bacteriology, 28(5) (1934)

21. Z. Guo, L. Zhang, Z. Ding, G. Shi, Metabolic Engineering, 13(1) (2011)

22. M.P. Naghshbandi, M. Tabatabaei, M. Aghbashlo, V.K. Gupta, A. Sulaiman, K. Karimi, Renewable and Sustainable Energy Reviews, 115 (2019) 